\title{
De piratas estrellados y flores carnívoras: una aproximación didáctica a Malapata III y la máquina del tiempo'
}

\section{Of Shipwrecked Pirates and Carnivorous Flowers: a Didactic Approach to Malapata III and The Time Machine}

\author{
ALICIA VARA \\ Universidad de Córdoba \\ España \\ avara@uco.es
}

(Recibido: I7-I2-202O; aceptado: I6-II-2O2I)

Resumen. La obra teatral Malapata III y la máquina del tiempo (María Rosal Nadales, 2019) no es una historia de piratas al uso. La autora vuelca en la pieza sus dotes como poeta y contadora de historias, de forma que ofrece una propuesta dramática en verso que combina referencias a la tradición literaria con una destacable actualidad en la confección de personajes y trama. El presente artículo tiene como objetivo analizar la tendencia de María Rosal a tomar elementos heterogéneos de la herencia culta o popular para reelaborarlos con el objetivo de crear un producto literario nuevo, destinado a cuestionar el sistema de valores imperante y estimular la ironía y el pensamiento crítico en el público infantil. Estamos ante una propuesta paródica y jocosa, que subvierte los códigos de la literatura infantil tradicional. Con este estudio se pretende profundizar acerca del valor de la obra teatral como herramienta artística y educativa y abordar las estrategias empleadas en Malapata III y la máquina del tiempo para captar la atención del público por medio de una acción dramática trepidante e irreverente.

Palabras clave: Historias de piratas; ciencia ficción; poesía infantil; teatro infantil; Educación Primaria.
Abstract. The theatrical work Malapata III and The Time Machine (María Rosal Nadales, 2019) is not your typical pirate story. The author weaves her talents as a poet and storyteller in such a way that she offers a dramatic approach in prose, combining references to literary tradition with a notable contemporary character and plot development. This article analyzes María Rosal's tendency of using heterogeneous elements in high and popular culture as a means to re-elaborate a new literary product meant to question the prevailing value system and stimulate irony and critical thought in children readers. What she suggests is nothing less than paradoxical and humorous, while also subverting traditional codes of children's literature. With this study we intend to delve into the value of theatre as an artistic and educational tool and to approach strategies used in Malapata III and The Time Machine to capture the audiences' attention by means of fast-paced, and irreverent, dramatic action.

Keywords: Pirate stories; science fiction; children's poetry; children's theater; primary education.

\footnotetext{
${ }^{\text {I }}$ Para citar este artículo: Vara, Alicia (2022). De piratas estrellados y flores carnívoras: una aproximación didáctica a Malpata III y la máquina del tiempo. Alabe 25 . [www.revistaalabe.com] 


\section{Introducción}

El teatro figura en el currículo de Educación Primaria como herramienta metodológica transversal óptima para la formación integral del alumnado, debido a su enorme potencial educativo y artístico. No obstante, la preparación y representación de textos teatrales no cuenta con una presencia significativa en las aulas, pues tiende a desplazarse al ámbito extraescolar o asignarse a fechas puntuales relacionadas con determinadas efemérides ${ }^{2}$. En efecto, "La educación literaria en la escuela ha girado tradicionalmente sobre la narración como género privilegiado de uso y explotación didáctica en el aula” (Llamazares y Selfa, 2OI6: 2). Esta tendencia lleva a relegar a un segundo plano a otros géneros como la poesía o el teatro, que podrían ser explorados en las aulas con grandes beneficios para la infancia (Bernardi, 20II). La escasa presencia del teatro en la escuela puede deberse a varios factores, como la falta de formación específica del personal docente acerca de cómo integrar estas prácticas en las respectivas materias, así como la ausencia de criterios sólidos para seleccionar o elaborar textos atractivos y motivadores (Caride, Trillo y Vieites, 2004; Llamazares y Selfa, 2OI6).

Estudios clásicos como los de O’Neill y Lambert (I982), Bolton (I986) y Tejerina (I994, I997, I999) sentaron las bases del potencial didáctico del teatro en la escuela. En la actualidad se sigue poniendo de relieve que este género promueve la capacidad humana de recrear universos heterogéneos y ampliar el propio imaginario, de forma que se facilita una aproximación respetuosa y profunda a la alteridad. Supone, en efecto, una vía para el conocimiento de culturas propias y ajenas, así como una oportunidad de encuentro comunicativo a nivel horizontal (Vieites, 2OI7).

A pesar de todas estas posibilidades educativas, conviene no desdeñar la oportunidad que ofrece el teatro para experimentar con los textos de una manera lúdica. De hecho, la pieza teatral que se propone en esta ocasión se ha seleccionando teniendo en cuenta sobre todo la necesidad de aportar al alumnado experiencias literarias divertidas y liberadoras, en las que -por medio de la expresión oral, corporal, cinética o gestual- sea posible tomar conciencia del propio cuerpo como herramienta de comunicación. Trabajar con teatro desde las primeras etapas educativas facilita abordar de forma temprana y desde una metodología activa tanto el lenguaje oral y escrito como la expresión corporal y artística. El alumnado parte de un texto base para descubrir sus posibilidades, experimentar con las palabras y construir, mediante el trabajo en equipo, una proyección espectacular destinada a un público determinado (Pérez Gutiérrez, 2004; Llamazares y Selfa, 20I6). Este tipo de actividad, de naturaleza social, contribuye a la mejora de relaciones en el aula y, al mismo tiempo, resulta una estrategia idónea para la promoción de la lectura (Osuna, 20I5).

\footnotetext{
${ }^{2}$ Torras i Albert (2OI2) pone de manifiesto la escasez de propuestas de este tipo en las aulas, acompañadas de directrices didácticas.
} 
No obstante, como se avanzaba, el profesorado de Educación Primaria carece de claves específicas para ejercer como figura mediadora con respecto a los textos teatrales, lo cual revierte en la falta de experiencias recurrentes y variadas en la escuela en las que el alumnado pueda interaccionar con este tipo de obras (Vieites, 2OI7) ${ }^{3}$. El presente artículo pretende poner de relieve la necesidad de apostar en las aulas de Educación Primaria por proyectos dramáticos, mediante la exploración de algunas posibilidades didácticas de dicho género.

A la vista de las necesidades detectadas en la comunidad educativa, esta propuesta tiene como objetivo ofrecer herramientas para capacitar al profesorado en la selección de obras teatrales adecuadas desde el punto de vista pedagógico pero también literario y artístico. En efecto, "Uno de los cuidados que debe tener cualquier docente es la selección de textos de calidad, es decir, textos cuya literariedad esté reconocida” (Llamazares y Selfa, 20I6: 2). A modo de ejemplo representativo, se realizará un acercamiento a la obra Malapata III y la máquina del tiempo, de María Rosal (20I9, Ediciones de la Huida), la cual resulta idónea para ser representada por alumnado de segundo ciclo de Primaria. Como se verá, esta pieza teatral, además de estar escrita en verso y ofrecer una oportunidad para experimentar con la métrica y el ritmo, ofrece en el nivel del contenido la posibilidad de trabajar en una línea coeducativa, pues plantea un cuestionamiento del androcentrismo habitual en la literatura infantil.

A menudo, se tiende a trazar una línea divisoria entre el juego dramático, que se utiliza de forma cotidiana en las aulas como herramienta didáctica, y el teatro propiamente dicho, reservado a ocasiones especiales, que cuenta con la particularidad de partir de un texto cerrado y orientarse hacia su representación ante un público. No obstante, ambas posibilidades pueden combinarse en el caso de Malapata III y la máquina del tiempo, pues resulta conveniente preparar al alumnado para la representación teatral por medio de actividades previas destinadas a la liberación expresiva. Asimismo, aunque nos centremos en una pieza concreta como punto de referencia y eje vertebrador de distintas actividades, resulta conveniente animar a los niños y las niñas a realizar aportaciones personales a los personajes y a la historia que están ensayando, sin desdeñar la posibilidad de improvisación.

De hecho, interesa mantener en las experiencias teatrales la importancia que la dramatización ofrece al proceso de preparación, de manera que se valore el camino que debe recorrer el alumnado para acercarse a los personajes, sumergirse en la trama y confeccionar el vestuario y los decorados. Esta fase de interacción con el texto, basada en la interpretación y la creatividad, debe ser valorada -y por ende evaluada- en la misma medida que la puesta en escena ante un público (Llamazares y Selfa, 20I6: 4). En esta línea, resulta imprescindible dejar al alumnado tiempo para que se exprese con espontaneidad, de manera que sus puntos de vista acerca de la construcción dramática afloren duran-

3 Para una aproximación a experiencias con teatro y dramatización en el aula de Primaria véanse, respectivamente, las propuestas de Torras i Albert (2OI2) y Llamazares y Selfa (2OI6). 
te los ensayos y las emociones resultantes sean validadas por el grupo. Este proceso de experimentación personal y social con el texto sirve para promover en el aula la libertad expresiva, facilitar el pensamiento crítico y cuestionar los estereotipos o prejuicios heredados.

\section{Una historia de piratas para el aula de Educación Primaria}

Es bien sabido que los relatos de piratas cuentan con un especial magnetismo, sobre todo entre el público infantil (Rodríguez y Morote, 20I6).

Por alguna razón siempre nos han cautivado las historias de piratas desde muy temprano, $[. .$.$] nos han atraído aquellas narraciones extraordinarias que cuentan toda clase de$ proezas legendarias sobre hombres arriesgados, capaces de cruzar los siete mares en la búsqueda de tesoros inimaginables. Impresas en nuestra memoria, continúan vigentes las imágenes de esos personajes pintorescos, arriesgados y valientes, que aún a costa de su propia vida siempre están dispuestos a emprender una nueva aventura (Ariza, Laiton, Manjarres y Pinzón, 20I8: 9).

¿Por qué resulta tan atractivo el personaje del pirata? Cabe registrar una serie de elementos iconográficos capaces de captar la atención del público, que se mantienen presentes en cualquier aventura de este género. A menudo, los relatos comienzan con rumores sobre un tesoro escondido en un cofre en una isla desconocida y un mapa que recoge indicaciones para localizarlo. Cuando el viaje ya es inminente, no pueden faltar el barco con la bandera pirata, brújulas que permitan orientarse en la búsqueda y otros artilugios que faciliten el proceso, como los catalejos con los que se otea el horizonte (Ariza, Laiton, Manjarres y Pinzón, 20I8). Cada uno de estos elementos estimula la imaginación del lector o lectora y hace aflorar la sorpresa o el temor ante los peligros del mar, la ilusión de encontrar el tesoro o la incertidumbre frente a lo desconocido. Recrear el motivo del viaje pirata genera un horizonte de expectativas que cautiva al público infantil y juvenil, ávido de aventuras.

Otro elemento constante en las historias de piratas es su carácter fantástico, lo alejadas que suelen estar del aquí y el ahora. En relación con este aspecto, ¿por qué resulta tan fácil identificarse desde nuestra realidad actual con personajes tan extraordinarios y novelescos? Quizá lo que llama tanto la atención sea su deseo irreprimible de surcar los mares en busca de la fama o su carácter astuto, que les permite salir con vida de las más peligrosas situaciones. Un pirata es capaz de orientarse observando las estrellas y conoce rutas marítimas insospechadas. Estas habilidades le permiten sobrevivir a terribles tormentas, gracias a un instinto de supervivencia a prueba de naufragios. No existe obstáculo ni adversario que detenga a un verdadero pirata en su deseo de explorar nuevos territorios: 
Ellos reemplazan sus manos con garfios, sus piernas con madera y sus ojos con vidrio cuando la adversidad los toma por sorpresa, los piratas emprenden toda suerte de travesías para encontrar los tesoros que colmarán las bodegas de sus buques, ya que el principal objetivo para ellos en realidad no es sólo apoderarse de las monedas de oro, sino lograr hacerse de un nombre y una reputación en altamar (Ariza, Laiton, Manjarres y Pinzón, 20r8: 9).

El interés que suscitan en la infancia este tipo de aventuras ha sido aprovechado en las aulas de Educación Primaria a través de distintas experiencias didácticas motivadoras, en relación con aprendizajes tan dispares como la resolución de problemas matemáticos o la lectoescritura (Rodríguez y Marote, 20ı6; Ariza, Laiton, Manjarres y Pinzón, 20I8).

A continuación, se analizará el potencial educativo y lúdico de la pieza seleccionada para este artículo, que cuenta con la particularidad de pertenecer al género teatral y de estar escrita en verso. De hecho, Malapata III y la máquina del tiempo (20I9) no es una historia de piratas al uso, pese a que muestra muchas características del género. Las referencias a los relatos de aventuras constituyen una de sus principales particularidades, si bien la incorporación de dichas alusiones en la obra no es directa y automática, sino que la autora ha realizado todo un proceso de transformación de los materiales de las fuentes al servicio de sus propias intenciones artísticas.

En efecto, además de que se aprecia un deliberado alejamiento del estereotipo del pirata como un peligroso y astuto criminal, tiene lugar un complejo proceso de adaptación de los contenidos del género narrativo clásico a las necesidades del teatro infantil contemporáneo. Se trata de una obra cuyo protagonista, el Capitán Malapata III, muestra - con algunos cambios- la iconografía habitual propia de sus modelos: pata de palo, garfio, parche en el ojo, sombrero y calavera. No faltan tampoco viajes cargados de imprevistos y obstáculos, así como la tradicional búsqueda del tesoro en islas perdidas. Sin embargo, cabe destacar que María Rosal no solo aborda la transposición genérica del molde narrativo al teatro en verso sino que, además, realiza una profunda labor de reescritura de los modelos heredados de la tradición. El resultado es la confección de una pieza con personalidad propia, conectada con los intereses e inquietudes del público del siglo XXI y muy poco sujeta a las convenciones del género.

A pesar de que el público al que está dirigida la obra se circunscribe a la etapa de Educación Primaria, Malapata III y la máquina del tiempo narra una historia que resulta atractiva también para una audiencia adulta, la cual sería capaz de identificar las referencias irónicas a la literatura clásica de aventuras, al tiempo que reconocería otras fuentes propias del imaginario popular. A la intención de distanciamiento y deconstrucción con respecto a la narrativa clásica de piratas se suma el enriquecimiento de la pieza con elementos de ciencia ficción, del cuento maravilloso tradicional, así como la presencia de algunos guiños cervantinos localizados en la conflictiva relación entre los personajes 
principales: Malapata III (trasunto del Quijote) y Profesor Garay (un Sancho contemporáneo). Cabría la posibilidad de realizar con el alumnado de Primaria algunas sesiones de acercamiento a dichas alusiones metaliterarias, con la finalidad de abrir un abanico intertextual sugerente y enriquecedor. Además, se podrían desentrañar en clase los componentes propios de las historias de piratas, teniendo en cuenta las diferencias de la obra analizada con respecto a las características básicas del género.

La historia arranca con el personaje de El Tiempo, "un anciano con barba muy larga" que "viste ropa clásica, como un rey del siglo XVIII" (p. I5). Se trata de un narrador que, pese a ser comparado con un monarca, se encuentra muy alejado de la apariencia ostentosa de estos personajes, habituales en la literatura infantil tradicional. De hecho, su vestuario se compone de prendas desgastadas - en jirones- y camina y se expresa de forma lenta, apoyado en un bastón (p. I5). El Tiempo, que produciría por su apariencia una reacción de extrañamiento en el público, facilita con sus intervenciones al inicio y al cierre de la pieza una estructura circular, muy bien trabada, la cual informa del esfuerzo de la autora por cuidar la dimensión formal de su obra. Dicha disposición simétrica podría ser apreciada por el alumnado como un rasgo propio del lenguaje literario y teatral.

Además, por medio de El Tiempo, se introduce la idea de que la acción representada constituye un episodio dentro de una serie más amplia. De este modo, dicho personaje se identifica como el hilo conductor de un ramillete de aventuras de piratas todavía no contadas, que nos transportan al modelo de La isla del tesoro (novela escrita por Robert Louis Stevenson). Se inicia, así, un juego de referencias destinado a la promoción de la lectura, que culminará en el epílogo de la pieza (p. 67), cuando el narrador anima al público infantil a buscar en las bibliotecas y en los libros más historias: “¿Queréis saber lo que ha pasado al Capitán Malapata y al Profesor Garay? ¿Queréis conocer sus nuevas aventuras? [...] Quizás algún día os las cuente. Mientras tanto, buscad en los libros, en las bibliotecas" (p. 67).

El Tiempo es el primer personaje (pero no el único) que potenciará la implicación del público en la obra, una estrategia que facilita una puesta en escena interactiva y estimulante. En los ensayos, será conveniente pedir al alumnado que preste una especial atención a aquellos pasajes que requieren de una intervención activa de la audiencia. Se recalcará la necesidad de que los actores y actrices utilicen la gestualidad y la expresión corporal para reforzar dicho contacto. Así pues, los canales comunicativos tendrían que mantenerse abiertos entre los participantes de la acción dramática pero también con respecto al público. En efecto, en varias ocasiones se localizan interpelaciones directas a los niños (y de forma explícita también a las niñas) que estarían contemplando la representación ${ }^{4}$.

\footnotetext{
${ }^{4} \mathrm{El}$ desdoblamiento de género se erige como estrategia para estimular la participación de la audiencia en las aventuras propuestas. Como ejemplo del uso deliberado del lenguaje inclusivo por parte de la autora figura en la obra una tribu caníbal, que aparece mencionada como un grupo hambriento "de la especie animal macho y de la especie animal hembra. Les gusta, sobre todo, la carne tierna de los niños y de las niñas" (p. 27) y selecciona sus víctimas entre el público.
} 
La acción arranca con una pareja de protagonistas compuesta por el Capitán Malapata III, un pirata frustrado porque es incapaz de encontrar un tesoro, y el Profesor Garay, un inventor loco. Se trata de dos compañeros de viaje antiheroicos y mal avenidos, que a menudo aparecen aturdidos o vencidos por infortunios. Las atractivas ilustraciones, a cargo de Tania Ávila Villalba, inciden en la comicidad y el carácter grotesco y estrafalario de dichos personajes. Así, en la propia portada se puede ver a un Capitán Malapata que muestra un gesto enfadado, ataviado como un pirata diminuto - con sombrero, calavera y demás parafernalia propia de su profesión-, frente a un Garay de rostro asustado, alto y esbelto, que combina parte del atuendo de pirata con rasgos más actuales, como el pelo violeta y unas grandes gafas. Estos personajes, que se construyen mediante la asimilación ecléctica de elementos iconográficos de distintas épocas, se oponen entre sí ya desde el plano físico, pero sobre todo parten de tradiciones literarias bien diferenciadas, de las que además pueden considerarse productos defectuosos.

Malapata III pertenece a un antiguo linaje de piratas, y comenzó su formación en la Escuela de Piratería con la intención de seguir la tradición familiar. Sin embargo, su incapacidad para encontrar tesoros le impide completar sus estudios. Lejos del carácter peligroso y arrogante que se atribuye a los piratas en los relatos tradicionales, el protagonista de esta obra teatral aparece humanizado: llora ante las adversidades y es incapaz de ejercer con éxito su profesión. Se aprecia aquí, como se verá en otros personajes, el firme propósito de María Rosal de revertir o cuestionar los roles y estereotipos propios de la literatura tradicional. Estos rasgos poco convencionales del protagonista podrían ser comentados con el alumnado de Educación Primaria, teniendo en cuenta la educación diferencial de género. También cabría analizar desde un punto de vista crítico la figura de los héroes de las historias clásicas, siempre representados como valientes y fuertes, en su tarea de conquistar territorios y salvar a princesas desvalidas.

Es precisamente el afán por encontrar tesoros lo que une los caminos de los dos protagonistas de la obra que nos ocupa. El Profesor Garay, conectado con la tradición de los relatos de ciencia ficción, resulta un trasunto paródico del protagonista de La máquina del tiempo, de Herbert George Wells. Aparece caracterizado como creador de vehículos espaciales, entre los que destaca una nave con detector de tesoros. Sin embargo, los anuncios que pone Garay para ganarse la vida de forma precaria desmitifican su figura de inventor y lo rebajan a la categoría de "chapuzas": "Profesor Garay / el inventor superway / (Máquinas del tiempo, coladores de estrellas, / brújulas y tesoros, chapuzas a domicilio)" (p. I 7$)$.

Dado el carácter fantasioso de ambos protagonistas, pronto se fragua una amistad fundamentada en el interés común por viajar en el tiempo y explorar el mundo, en busca del éxito y la fama. La principal estrategia en la elaboración de estos personajes es dotarlos de un quijotesco idealismo y una voluntad épica que choca frontalmente con las situaciones ridículas en las que se ven envueltos. En efecto, el narrador relata un sinfín de aventuras frustradas, en las que Malapata y Garay aparecen casi devorados por un dinosaurio, encarcelados en un castillo medieval o al borde de la muerte en un circo romano 
(pp. I7-I8). Estas historias desastrosas, que se van encadenando hasta el final de la pieza, están destinadas a llamar la atención de los niños y niñas por la vía del humor y la imaginación ${ }^{5}$. En sus desventuras cada vez más peligrosas, los dos personajes principales son retratados "vestidos de piratas con las ropas destrozadas" y se dice de ellos que están "medio atontados" (p. I9).

Al llanto de Malapata III frente a los peligros se suma la incapacidad de Garay para superar obstáculos, pues en los momentos de tensión cae desmayado (p. 2I). Ambos se espantan frente a lugares nuevos y exóticos en los que encuentran "plantas raras", "feas" o "monstruos verdes" (p. 2O). Ante la presencia amenazante de la Reina de las Flores Carnívoras, "Malapata y Garay tiemblan, se encogen y abrazan aterrorizados" (p. 6o). En lugar del celebrado carácter intrépido de los piratas tradicionales, la peculiar pareja se muestra derrotada: "Qué tesoro ni ocho cuentos, hemos perdido hasta el loro. [...] ¡Oh, qué desgracia tan grande!” (p. 22).

Esta caracterización antiheroica y poco convencional permite abordar en el aula de Primaria el cuestionamiento de los referentes culturales y los relatos heredados. Se promoverán las interpretaciones creativas y humorísticas de los episodios de la obra a partir de preguntas como: ¿Tú cómo reaccionarías si te encuentras con las flores carnívoras? ¿Te identificas más con Garay y Malapata III o con los piratas clásicos? ¿Qué aventuras te parecen más divertidas?

Por otro lado, el lenguaje utilizado por los protagonistas de Malapata III y la máquina del tiempo facilita la proximidad con el público infantil, pues a menudo recurren a la expresividad, a la parodia y a las bromas para narrar sus avatares y plasmar su desconcierto. Esta característica permite acercarse a los distintos registros lingüísticos que pueden utilizarse en un escenario. El registro coloquial se marcará como una característica constante a lo largo de la obra y se pediría al alumnado que piense en situaciones de su vida real en las que se utilice el lenguaje de esa manera ${ }^{6}$.

Además, como se adelantaba, cabe tener en cuenta el aire quijotesco y arcaizante que adoptan algunas de las intervenciones de Malapata, que utiliza léxico anacrónico y expresiones como "tunante" (p. 22), “afrenta" (p. 50), “malandrines” (p. 50) o “iQué diantre!” (p. 22), lo cual refuerza su condición de héroe paródico o caballero andante frustrado. Esta selección léxica resultará llamativa para el alumnado de Primaria, que podrá aproximarse a la figura cervantina a través de su trasunto pirata. En esta línea quijotesca destacan los ataques de ira desmesurados de Malapata, que podrían ser considerados por la clase en relación con la necesidad de saber gestionar las emociones. En efecto, el protagonista de la obra muestra un escaso control de la ira, a menudo vertida contra su aterrorizado ayudante: "Te he de colgar en el árbol más alto de este lugar / y dejaré que los pájaros te tomen por un manjar” (p. 22).

\footnotetext{
5 Para un estudio sobre la pertinencia de utilizar desde las primeras etapas educativas obras literarias de temática fantástica, ver Rodríguez Pascual y Vara López, 20I9.

${ }^{6}$ Se les podría pedir, incluso, que aportasen anécdotas graciosas en las que se hubieran sentido fuera de control, como les ocurre a los personajes: sorpresas inesperadas, caídas, intentos fallidos de mentir, momentos en los que todo sale mal, etc.
} 
Por otro lado, el nombre pomposo con el que se presenta al protagonista, "Capitán Malapata III", resulta ridículo a la luz de sus infortunios, aspecto que podría comentarse en el aula para aproximarse al recurso literario de la paradoja ${ }^{7}$. En relación con esta misma tendencia desmitificadora, el oxímoron y el uso de elementos de atrezo anacrónicos se alzan como recursos idóneos para transgredir los códigos de las distintas tradiciones literarias que se conjugan en la obra, de manera que se instaura una ambientación híbrida basada en la ironía y la cercanía con el público. Podría ser pertinente descubrir con el alumnado aquellos elementos de atrezo impropios de los relatos clásicos de piratas (las gafas y el tinte violeta de Garay, un teléfono móvil o una nave espacial a modo de máquina del tiempo). Asimismo, se podría identificar el eclecticismo en la combinación de fuentes: sobre todo, se destacarían ingredientes del relato de ciencia ficción, del de aventuras, de la narrativa de piratas y de los cuentos de hadas tradicionales.

En cuanto a la alteración de los patrones genéricos de los cuentos maravillosos, llama la atención el momento en el que el Jefe de la Guardia Real, personaje que en la tradición suele protagonizar escenas ceremoniosas, aparece ante la reina rebajado a la condición de un criado servil y ridículo: habla por el móvil con la monarca y, a continuación, se presenta ante ella con "una reverencia exagerada" (p. 54). A pesar de la alteración de algunos rasgos y de las licencias cómicas, el guardia mantiene su función de portador de misivas y transmite un mensaje crucial para el desarrollo de la acción dramática. En concreto, enumera a la reina, en el tono humorístico propio de la pieza, los derechos de la infancia: "Según altos tribunales, / protegen a los mocosos / leyes internacionales. / Todos los niños y niñas / tienen derecho a vivir / y a no servir de pitanza / a las carnívoras flores. [...] Tienen derecho / a que los padres les lean / cada noche al ir al lecho / todos los cuentos que quieran" (pp. 58-59). Con su intervención, el Jefe de la Guardia Real no muestra gran aprecio por los niños y niñas del público, a los que llama “mocosos". No obstante, de acuerdo con las normas vigentes, los salva de un destino trágico. Al mismo tiempo, en su discurso se aprecia una vez más el interés por mostrar la lectura como una actividad lúdica y atractiva en la infancia, elevada a la categoría de "derecho". Alrededor de esta escena, podría realizarse en el aula de Primaria una actividad consistente en redactar derechos de la infancia en clave cómica, centrados en todo aquello que le gustaría hacer al alumnado a diario (jugar y levantarse a cualquier hora, por ejemplo). De esta manera, estarían recreando una escena de la pieza y conectándola, a través del humor, con sus propios gustos y preferencias ${ }^{8}$.

Por otro lado, María Rosal pone énfasis en nombrar y otorgar protagonismo a los personajes femeninos, a los que dota de personalidad, lejos de la tendencia androcéntrica de la literatura infantil más tradicional que a menudo se limita a asignarles estereotipos.

\footnotetext{
7 Se podría animar a los niños y niñas a que buscasen sus propios nombres de piratas, de forma que utilizasen características reales o imaginarias. Así, les motivaríamos a interaccionar con la obra desde una perspectiva creativa y humorística.

8 También cabría la posibilidad de realizar una actividad con los verdaderos derechos de la infancia, con ejemplos concretos para su comprensión.
} 
En este sentido, merece especial atención el caso de la Reina de las Flores Carnívoras, personaje de carácter amenazante y autoritario, que transgrede los códigos habituales de belleza femenina. De hecho, se describe como una "margarita con boca exagerada y unos dientes terribles" (p. II), rasgos que concuerdan con su gran voracidad. La reina se encuentra rodeada de un séquito de flores carnívoras, que -si bien aparecen formando un arcoíris con sus colores llamativos - se alejan deliberadamente del rol de las bellas damas cortesanas de los cuentos maravillosos.

La deconstrucción de los estereotipos femeninos se sustenta en el rechazo de la delicadeza, la dulzura o la disponibilidad que se atribuye a mujeres y niñas en los relatos tradicionales. En este caso, las flores dejan de contar con una función ornamental y pasiva, que podría conectarse con los mandatos de belleza y sumisión. En su lugar, en Malapata III y la máquina del tiempo, las flores (y su reina) se caracterizan por su condición carnívora y su voracidad, rasgos que las impulsan a capturar a los protagonistas y a amenazar al público con ser engullido. En efecto, la flor Violeta se muestra despectiva con Malapata III y Garay, a quienes les dedica apelativos como "aprendiz de almirante", "piltrafa" y "mamarracho", mientras que Hortensia les llama "sucios y apestosos" (p. 48). Es obvio que la autora rechaza la identificación de los personajes femeninos con la vocación por los cuidados, la hospitalidad y la renuncia a los propios intereses para servir a otros ${ }^{9}$.

Si se atiende a las ilustraciones, resulta especialmente llamativa la página $5^{2}$ del libro, que muestra el círculo de flores en plano contrapicado, con sus dientes afilados y vistas en actitud amenazante por parte de los prisioneros. Se refuerza aquí el propósito de subvertir los códigos narrativos tradicionales, pues se da la paradoja de que los piratas, con su halo de criminalidad, son capturados por las flores y se muestran aterrorizados e indefensos ante ellas. De hecho, la reina, con su séquito, sustituye al habitual personaje masculino que ostenta el poder real en los cuentos tradicionales, si bien se le otorga un carácter maligno. Su estatus se refuerza con una actitud dominante y un "vestuario rico y simbólico" (p. 45).

En un contexto de acción trepidante y constantes sorpresas y giros, la tribu caníbal, que entronca con las que aparecían en el modelo clásico de aventuras, se dirige al público a través de la música y el baile y utiliza un léxico muy poco habitual en el género ${ }^{\mathrm{IO}}$. Se trata de referencias al ámbito de la cocina, en conexión con la consideración de la audiencia como posible vianda ("morcilla", "chuletas", "escalopes", "sorbete", "filete empanado”, “albóndigas y estofado, sopa y salsa boloñesa”, pp. $3^{\mathrm{I}-32}$. El tópico de devorar a los niños y niñas, presente también en los cuentos tradicionales, se traslada en este caso a un terreno humorístico, en tanto que la tribu aporta detalles y ejemplos culinarios muy

\footnotetext{
${ }^{9}$ Estas características son habituales en las hadas o las damas de la corte.

Io Estos episodios con tribus caníbales beben de relatos surgidos a partir de la paradigmática novela Las minas del rey Salomón, de H. Rider Haggard (1885).
} 
prosaicos que sirven para rebajar la carga de violencia de la escena": "Con mucha sal y orégano adobamos chuletas / de niños y de niñas, de profes majaretas” (p. 28). De este modo, el público se sentiría constantemente interpelado y partícipe de las aventuras que se representan en el escenario. En efecto, más adelante, la Reina de las Flores se dirige al Jefe de la Guardia Real y afirma que, antes que recurrir a Malapata y Garay, "prefiere comerse a un niño de la tercera fila o a aquella niña de la fila segunda, que están más gorditos y lustrosos y seguro que más tiernos para sus pobres muelas gastadas” (p. 54). Se registra, así, una tendencia constante a combinar pasajes de gran intensidad dramática con detalles humorísticos, destinados a activar al público por medio de la sorpresa y la interacción.

Por otro lado, la pieza se nutre de una mezcla de géneros y referencias intertextuales de raigambre popular: sirva como ejemplo el empleo de la fórmula de la receta $o$ el conjuro por parte de la tribu caníbal ${ }^{12}$. En estos pasajes existen ecos de la obra poética de María Rosal, llena de alusiones irónicas a léxico culinario, tradicionalmente asociado al universo femenino ${ }^{\mathrm{I}}$. Este vocabulario propio del ámbito de la cocina trasladaría al público a los espacios domésticos y de cuidados, tan alejados de las historias de aventuras ${ }^{\mathrm{I}}$. Una vez más, se busca desmitificar a los personajes malvados de la narrativa de aventuras y dotarlos de un halo de cotidianidad.

A todo ello cabe reiterar que la danza festiva de la temida tribu caníbal, acompañada de cantos en coro, sirve para provocar una situación de constante alarma en el público, aunque prevalecería un tono humorístico y lúdico: "Que si quieres que te coma, / que si quieres que te coma, / que si quieres que te coma, / que si quieres que te coma. / Hum, Hum, Hum", p. 3o; "Somos los caníbales, / Hum, Hum, Hum. / Somos los caníbales, / Hum, Hum, Hum” (pp. 32, 33). La presencia, en las ilustraciones, de saleros de tamaño descomunal - portados por terroríficas criaturas- añade ecos de la corriente del nonsense, que transportan al público a un universo de fantasía (pp. 30-3I). Esta escena tan rica en referencias continúa con la declamación, a tres voces, de una detallada receta en verso, con reminiscencias de la fórmula de los conjuros (pp. 33-34) (15. $^{15}$

\footnotetext{
${ }^{\text {II }}$ A todo esto hay que añadir que la tribu estaría compuesta, no de personas adultas, sino de niños y niñas.

I2 Sería acertado trabajar en el aula con recetas tradicionales o familiares, de manera que este legado, a menudo invisible, se pondría en valor desde el ámbito educativo. Cabría la posibilidad de realizar alguna dinamica intergeneracional en la que las abuelas transmitieran algunos de sus conocimientos culinarios a sus nietos y nietas, dejando claro que este saber es fundamental tanto para los niños como para las niñas. Si participasen los abuelos (y los padres) esta transferencia de saberes ganaría en potencial coeducativo.

${ }^{13}$ En concreto, se localizan conexiones con la obra infantil de María Rosal Conjuros yotras brujerías (2007), la cual también podría abordarse en las aulas de Primaria.

${ }^{\text {I4 }}$ El pasaje podría dar pie a posteriores actividades de reflexión acerca de la corresponsabilidad de los dos sexos en las tareas domésticas y de cuidados. El objetivo principal es fomentar el pensamiento crítico acerca de la división tradicional de roles y reconocer el valor del trabajo invisible que históricamente han desempeñado las mujeres.

I5 Al finalizar la obra podría pedirse al alumnado que crease sus propios conjuros, destinados a resolver problemáticas que pueden partir de lo cotidiano o contar con un alcance más social. De esta forma, se verbalizarían las inquietudes e intereses de la clase y se pondrían en común las posibles soluciones. El conjuro actuaría como un estímulo lúdico para facilitar la interacción.
} 
Esta hibridez referencial, presente a lo largo de toda la obra, se completa con una alusión a las adivinanzas infantiles, en boca de un caníbal que agarra a un niño del público. En este caso, mientras se lleva al pequeño en un momento de interacción y juego, pronunciaría lo siguiente: "Adivina, adivinanza, / ¿quieres ser tú mi pitanza? / Vamos, que si quieres que te coma" (p. 29). Otra posible actividad posterior a la representación sería que el alumnado investigase en su entorno para recopilar adivinanzas, que se pondrían en común en el aula en una sesión lúdica.

Todos los recursos expresivos y literarios de diversa procedencia se combinan con el propósito de lograr un efecto de comicidad en escenas muy dinámicas, destinadas a suscitar en el público al mismo tiempo sorpresa, tensión ante el peligro de ser engullido por la tribu y, sobre todo, mucha diversión. En los distintos pasajes se alude a materiales conocidos de antemano por el alumnado, como los cuentos tradicionales, los conjuros, las recetas y las adivinanzas. Así, se logra tender un puente entre el mundo fantástico y lejano de las aventuras de piratas y los referentes cotidianos de los niños y niñas.

Si se tiene en cuenta el carácter desenfadado de Malapata III y la máquina del tiempo, basado en el diálogo constante con la tradición de las novelas de aventuras, no resulta baladí que la argucia que utiliza Garay para librarse del cautiverio y la muerte al final de la obra sea retomar un elemento iconográfico propio de las historias de piratas: el ron. La acción dramática concluye con una escena de música y baile protagonizada por Garay y Malapata, quienes - para evitar ser devorados- tratan de distraer a la reina y sus flores con un sonsonete que nos transporta a las aventuras de Long John Silver en La isla del tesoro: "Ron, ron, la botella de ron. / Ron, ron, la botella de ron. / Ron, ron, la botella de ron" (p. 65). A pesar de la primera reacción por parte de la reina de desprecio absoluto hacia los cantantes, ellos continúan con su plan de incitar a la fiesta, bien instaurados en su rol de piratas vitalistas. Así, lejos de amilanarse ante el peligro palpable, siguen cantando hasta que logran aplacar la ira y la voracidad de la dirigente de la isla. Es en ese momento cuando ponen en marcha su estrategia, que consiste en presumir, de manera intrigante, de un misterioso tesoro que estaría escondido en su nave: se trata de "un licor tan secreto / que es importante probar / antes que cualquier manjar” (p. 62). La pareja logra así que la curiosidad de sus enemigas sea más fuerte que el hambre, de forma que las flores y su reina pronto caen en la trampa de querer disfrutar de dicha bebida desconocida, antes de devorar a los piratas. Como en este caso el orden de los factores sí altera el producto resultante, la reina y su amenazante séquito caníbal beben ron hasta dormirse, incapaces de seguir con el plan de devorar a los visitantes. En este momento, Malapata y Garay, que por fin logran aplicar una argucia propia de piratas, huyen en su máquina del tiempo.

Bien es cierto que su suerte no cambia en este episodio, pues otra vez se salvan por los pelos de la muerte y se marchan con las manos vacías de tesoros, sin superar la maldición de verse otra vez como piratas sin botín. No obstante, a pesar del fracaso, estos personajes cumplen a la perfección la función dramática que la autora les asignó en su momento: desplegar un universo fantástico lleno de sorpresas, humor y descubrimientos y superar -aun sin ser valientes- peligrosos obstáculos. El Capitán Malapata III y 
el inventor Garay no dejan de soñar con nuevas aventuras. En su condición de piratas y viajeros inexpertos, normalizan que en la ficción, como en la vida real, en ocasiones los planes no salen como se esperaba. Lanzan, así, el mensaje de que es habitual equivocarse, enfadarse, asustarse e incluso llorar.

\section{Conclusiones}

Si hay un componente que predomina a lo largo de la obra y sobresale frente a todo lo demás es la comicidad, que impregna los distintos niveles dramáticos. Este elemento se localiza ya en el propio título y se desarrolla en los parlamentos de los personajes, las expresivas ilustraciones y hasta en las acotaciones. El enfoque humorístico omnipresente dota de unidad y coherencia al conjunto de la pieza y, además, como estrategia compositiva, contribuye a cuestionar los estereotipos de género habituales en los relatos tradicionales de piratas y en la literatura infantil en general. En efecto, los personajes femeninos se apartan de los mandatos de pasividad, belleza, sumisión y complacencia, para situarse en una posición activa y desafiante. Por su parte, Malapata y Garay actúan en clave antiheroica, de forma que se abre en el aula de Primaria una puerta al cuestionamiento de la figura arquetípica y androcéntrica del héroe.

Sin desdeñar estos aspectos que ponen de relieve el potencial didáctico de Malapata III y la máquina del tiempo, cabe dejar claro que el punto fuerte de la obra no radica en su propósito educativo, sino en la dimensión lúdica y artística. En efecto, la pieza logra captar la atención a través de una acción dramática trepidante y sorprendente. Las diversas referencias y fuentes literarias se funden en una propuesta irreverente, ajustada a las necesidades del público infantil del nuevo milenio. Los niños y las niñas de Primaria, con la adecuada mediación, participarán en la construcción de una puesta en escena divertida y, al mismo tiempo, accederán a una experiencia de inmersión en un universo fantástico lleno de aventuras.

A todo ello se suma el gran potencial espectacular de la pieza, explorado ya en la representación realizada bajo la dirección de José Sierra (20I8). La elaboración de vestuario y decorados a partir de las ilustraciones y las descripciones que aparecen en la obra supone una oportunidad más para interaccionar desde el aula de manera personal y creativa con el texto, los personajes, la acción dramática y los espacios que se despliegan a lo largo de las escenas.

Además, cabe reiterar que en la composición de Malapata III y la máquina del tiempo María Rosal cuida el componente estético y la estructura dramática, sin subestimar la inteligencia del público infantil para apreciar distintos recursos formales. En este sentido, la obra, lejos de caer en simplificaciones o tramas edulcoradas, conecta con los niños y niñas de Educación Primaria por medio del humor y la ironía, en una invitación constante a trascender géneros, convenciones y mensajes cerrados. De acuerdo con un propósito de poner en el centro del escenario la invitación a la aventura y el juego con las 
palabras, la pieza entra de lleno en una corriente de literatura infantil que apuesta por el despliegue de la imaginación y la creatividad.

Con esta aproximación didáctica a una obra actual se han mostrado distintas estrategias para facilitar al alumnado de Primaria encuentros con el teatro. En este recorrido, se ha tratado de poner el foco más allá de la carga didáctica que contiene en efecto cualquier material literario. El propósito de alcanzar el máximo nivel de aprendizaje, legítimo en muchas de las actividades del aula, debería cuestionarse cuando se está trabajando con experiencias teatrales, donde el principal objetivo - sin el cual la actividad perdería todo sentido- es facilitar a los niños y las niñas la oportunidad de sumergirse, a través de los ojos de los personajes, en una historia cautivadora. 


\section{Referencias bibliográficas}

- Ariza Guevara, J.C.; Laiton Pinzón, S.L.; Manjarres Velasco, G.A. y Pinzón Fajardo, W.Z. (2018). Entre piratas y tesoros: narraciones del Píleo en el contexto del Colegio Germán Arciniegas. Obtenido el 9 de abril de 202 I desde:

https://repository.usta.edu.co/handle/II634/ı3II7

- Bolton, G. (1986). Freedom and imagination- and the implication for teaching drama. En D. Davis y C. Lawrence (Eds.). Gavin Bolton: selected writings (pp. I8-22). Londres: Longman.

- Caride, J.A.,Trillo, F. y Vieites, M. (2004). Arte Dramática e función docente. Santiago de Compostela: Consello da Cultura Galega, 2OO4. Obtenido el 9 de abril de 2O2I desde: http:// consellodacultura.gal/publicacion.php?id $={ }_{27} 6$

- Llamazares Prieto, M.T. y Selfa Sastre, M. (20I6). La dramatización de poemas infantiles: algunos ejemplos de trabajo para el aula de Educación Infantil y Primaria. Álabe, I4, 2-22. DOI: http://dx.doi.org/IO.I5645/Alabe2OI6.I4.4

- O’Neill, C. y Lambert, A. (1982). Drama structures: a practical handbook for teachers. Londres: Hutchinson.

- Osuna G., M.A. (20I5). Por qué la integración del teatro en el proceso de enseñanza del nivel de Educación Primaria. Mucuties Universitaria, 3, 48-57.

- Pérez Gutiérrez, M. (2004). La dramatización como recurso clave en el proceso de enseñanza y adquisición de las lenguas. Glosas didácticas. Revista Electrónica Internacional, ı2, 70-80.

- Rider Haggard, H. e Izquierdo, M. (Trad.) (2020). Las minas del rey Salomón. Madrid: Editorial Verbum.

- Rodríguez Hernández, M.M. y Morote Esquivel, O. (2OI6). ¡Jugamos a detectives y piratas! Aplicación de un programa de aprendizaje sobre resolución de problemas. Números. Revista de Didáctica de las Matemáticas, 93, 45-73.

- Rodríguez Pascual, R. y Vara López, A. (2019). La fantasía en el álbum ilustrado infantil. Álabe, 2O, I-25. DOI: http://dx.doi.org/IO.I5645/Alabe2Or9.20.5. Artículo obtenido el 9 de abril de 2O2I desde:

http://revistaalabe.com/index/alabe/article/view/470

- Rosal Nadales, M. (2007). Conjuros y otras brujerías. Madrid: Hisperión.

- Rosal Nadales, M. y Ávila Villalba, T. (Ilustr.). (2OI9). Malapata III y la máquina del tiempo. Sevilla: Ediciones en Huida. 
- Stevenson, R.L. y Caballero, M. (Trad.) (20I5). La isla del tesoro. (s/l): FV Éditions. Obtenido el 9 de abril de 2O2I desde:

https://books.google.es/books?id=vZhpCgAAQBAJ\&printsec=frontcover\&dq=la+isla + del + tesoro+libro\&hl=es\&sa=X\&ved=2ahUKEwjWxdOYifHvAhVBOBoKHXjWCHkQ6AEwA noECAIQAg\# $\#_{\mathrm{v}}=$ onepage\&q=la\%2oisla\%2odel\%2otesoro\%2olibro\&f=false

- Tejerina, I. (1994). Dramatización y teatro infantil. Dimensiones psicopedagógicas y expresivas. Madrid: Siglo XXI.

- Tejerina, I. (I997). Teatro infantil y dramatización escolar. En P. Cerrilloy J. García (Coords.) Teatro infantil y dramatización escolar (pp. 97-II8). Cuenca: Ediciones de la Universidad de Castilla-La Mancha.

- Tejerina, I. (1999). El juego dramático en la Educación Primaria. Textos. Didáctica de la Lengua y la Literatura. Monográfico Teatro y juego dramático, I9, 33-44.

- Torras i Albert, A. (2OI2). El teatro en la escuela: un proyecto municipal de incentivación del teatro como actividad formativa, cultural y artística. Dedica. Revista de Educação e Humanidades, 2, 2OI-2I6.

- Vieites, F. (20I7). La Pedagogía Teatral como Ciencia de la Educación Teatral. Educação \& Realidade, 42(4). Artículo obtenido el 9 de abril de 2O2I desde:

https://www.scielo.br/scielo.php?script=sci_arttext\&pid=S2I75-62362OI7O0O4OI52I\&lng $=\mathrm{es} \& \mathrm{t} \operatorname{lng}=\mathrm{es}$

- Wells, H.G. y Padrón, A. (tr.) (2Org). La máquina del tiempo. Madrid: Editorial Verbum. 